\title{
Enterprise Social Network Applications: Enhancing and Driving Innovation Culture and Productivity Through Digital Technologies
}

\author{
Kaveh Abhari \\ San Diego State University \\ kabhari@sdsu.edu
}

\author{
Nathan Ascue \\ San Diego State University \\ nascue@s,sdsu.edu
}

\author{
Cooper Boer \\ San Diego State University \\ cboer@sdsu.edu
}

\author{
Christopher Sahoo \\ San Diego State University \\ csahoo@sdsu.edu
}

\author{
Mahsa Zarei \\ San Diego State University \\ mzarei@sdsu.edu
}

\begin{abstract}
Enterprise Social Network (ESN) applications offer new opportunities for organizations to mobilize employees, promoting innovation beyond traditional $R \& D$ functions. Despite the popularity and success of these applications, current research has yet to fully explore the potential of ESN applications as both drivers of productive innovation and innovation culture, specifically. This paper proposes a theoretical framework that explains the role of ESN applications in facilitating organizational-wide ideation, collaboration, and socialization, thereby promoting innovation culture and innovation productivity. This study reveals that the dimensions of innovation culture, namely knowledge sharing, transparency, and risk tolerance, mediate the effects of ESN applications on the measures of firm innovation productivityproduct/service innovation, process innovation, and social innovation. The findings presented here have implications for theory and practice, namely concerning building an organizational culture that promotes open innovative behavior using social technologies.
\end{abstract}

\section{Introduction}

Innovative value-creation is theorized to be the key driver of success for many modern organizations. According to McKinsey, $84 \%$ of firm executives believe that their future success is only sustained by continued innovation [1]. Recently, the implementation of Enterprise Social Network (ESN) applications to improve innovation has drawn the attention of many organizations, with ESN technologies and software purporting to enhance collaboration practices, facilitate knowledge sharing, and strengthen effective communication [2] beyond functional boundaries [3]-[5]. These tools are used in developing new products and services, as well as in improving the social processes and impact of intraorganizational collaboration [6], [7]. Despite these promising applications, some researchers are still skeptical of the impact ESN applications have on innovation due to the complexity of the innovation process in general [8]-[10]. This speculation corresponds with current debates around the role of social technologies in enabling [11] or facilitating a new form of innovation [12]. As such, we believe that further explication of the innovation process is due attention, specifically through the lens of ESN applications.

Understanding the role of ESN apps in cultivating innovation can aid in evaluating the practicality of social integration via ESN as a means of turning employees' creative potential into innovative assets and useful versatility [13]. Therefore, this study aims to provide a nuanced, practical frame of reference for understanding the nature of ESN apps and their relationships to innovation culture and innovation productivity. We offer a systematic method to model ESN application use by applying functional affordances as a theoretical lens [14], and characterize ESN platforms as digital technologies affording ideation, collaboration, and socialization for innovation [15]-[17]. While our model is grounded in theory, it attempts to account for the unique character of different ESN platforms.

Additionally, we identified innovation culture as a mediator between ESN applications and innovation productivity. This mediating relationship explains why previous studies regarding ESN apps and innovation productivity reported inconclusive results. This study thus offers a new way to consider, select, and apply ESN platforms to boost innovation productivity in modern organizations. 
This paper begins with a literature review that details the theoretical foundations of our study. In this synthesis of existing research, we illuminate the underlying mechanism between ESN and product, process, and social innovation. Following this literature review, we present our theoretical model along with detailed descriptions of the hypotheses comprising it. Then, section four describes methods of data collection and analysis that follows with the discussion of the results. Finally, we offer a discussion of results and contribution of this research to both theory and practice, concluding with limitations and implications for future research directions.

\section{Research Background}

The application of new technology, new organizational structures, and/or new administrative systems to improve efficiency and efficacy are key components in the process of innovation. In that vein, prior research on innovation reveals that new product and service development helps organizations maintain a competitive edge in their immediate marketplace [9], [18]. ESN applications offer affordances to firms that can facilitate the process of new product or service development by "opening" the ideation process and promoting greater socio-professional interaction and collaboration among employees [19]-[21]. Thus, it is critical to understand the innovation process for developing business theory intent on aiding the longevity of firms in a digital space.

Further, innovation productivity involves business processes critical to achieving organizational goals and enhances organizational performance and growth [22], [23]. To aid this, ESN applications facilitate the generation of new process ideas, as well as their experimentation and implementation [24]. As such, the involvement of ESN applications in organizational culture is a paramount consideration to firms aiming for high innovation productivity.

Organizations may also "reinvent" themselves in terms of social impact [25], [26]. This idea closely relates to the notion of social innovation, which emphasizes "innovation" as a necessary component of generating social value [27]. Thus, identifying the enablers of social innovation, including ideation and validation, is of interest of researchers [28]. This is especially relevant, as ESN applications empower employees to participate in the social innovation process and voice their opinion as part of social validation [29]. Therefore, in the context of this study, innovation productivity is conceptualized as the sum of organization productivity in introducing new products/service, processes, and positive social impact (cf. [30]).

\subsection{Innovation Culture}

Innovation culture refers to "the extent to which a company is suitable for developing innovation or whether it resists innovation" [34, p. 135]. Innovation culture is thus an interpretive framework through which employees make sense of their innovative contribution, as well as their organizational commitment to the innovation process [30]. In this study, innovation culture is characterized by three critical dimensions: Knowledge Sharing, Transparency, and Risk Tolerance.

Innovation culture is an antecedent to innovation productivity since the former requires shared values, assumptions, and beliefs [31]. Additionally, innovation goals are easier to achieve in organizational cultures that have institutionalized the value of change [32]. Thus, a company that facilitates change within its organizational culture can continually innovate [33].

2.2.1 Knowledge-sharing. Knowledge-sharing is a trait of organizational culture. This trait defines the employee's perception and attitude toward open knowledge exchange within set boundaries [35] fostering an organization's ability to continuously learn and innovate [35]. As a cultural value, knowledge-sharing helps improve innovation performance by enhancing collaboration and employee engagement in participatory problemsolving [36], [37]. Thus, technology-enabled mechanisms for internal knowledge sharing like Slack, Microsoft Team, and Yammer, pushing collaboration a step further by increasing communication inside and outside of the organization.

2.2.2 Transparency. Transparency refers to openness in reporting, communicating, and discussing opportunities, challenges, errors, or failures within an organization's boundaries [38], [39]. Transparency is a trait of cultural organization that supports innovation through openness to new ideas and/or learning from failures. Transparency also reduces managerial career concerns and thus supports innovation initiatives across business units [40]. Open reporting and soliciting feedback on innovation initiatives can also boost innovation productivity. When employees are allowed and encouraged to be open in both ideation and criticism, new ideas emerge and refine faster which in turn improves innovation. ESN platforms supporting such openness can be utilized to promote the culture of transparency by practically showing its values, limits, and implications [41]-[43].

2.2.3 Risk Tolerance. Risk Tolerance is an important factor when it comes to innovation culture. Successful organizations understand that failure is a natural part 
of the innovation process [44], and research suggests that tolerance for risk, change, and failure are prerequisites of any form of innovation [45]. In traditional work cultures, fear of failure discourages employees from sharing new ideas or participating in any new idea development. In a risk-taking culture, however, employees are granted permission to experiment with new ideas, encouraged to collaborate with their colleagues and customers, and empowered to make decisions regarding new initiatives [46]. Companies that lack support for risks inadvertently not only hurt their chances of spurring the next big idea but also fail to retain their creative talents [8]. Thus, ESN aids innovation teams in managing risks associated with new ideas development, team collaboration and performance, and interdepartmental communication, therefore helping organizations to assess risks and contingencies from a broader perspective [41].

\subsection{ESN Applications}

Organizations can become more innovative by going beyond traditional $\mathrm{R} \& \mathrm{D}$, capitalizing on the insights and ideas of all employees [8], and mobilizing them to innovate organically [47]. ESN applications are uniquely suited to this task.

ESN applications are commonly used by many organizations to support organizational routines such as communication, relationship building, information sharing, problem-solving, project management, and task coordination [48]. To model ESN application usage options, we use "functional affordances" as a theoretical lens [14], and summarily define it as a set of key action possibilities offered by typical ESN platforms [15], [49]. This allows us to study ESNs by the measure to which they afford innovation-related actions across different tools [4]. Using functional affordances as a theoretical lens instead of features aids us in studying a wide range of ESNs, independent from their differences in implementation.

ESNs offer features such as user profiling, status updates and content sharing, micro-blogging, group management, instant and private messaging, enterprise search and archiving rating and supporting ideas, and the ability to connect with or follow other members of the community [38], [49]. These features support three forms of actions in innovation context: ideation, collaboration, socialization [17].

Ideation is specified as a process of generation and development of new ideas for problem-solving (it is not to be confused with innovation; ideation is to propose a new concept or rough idea while innovation is the full development and actualization of that concept or idea). By affording ideation, ESNs foster openness, creativity, and innovativeness among employees. ESNs offer various features that can individually or collectively afford ideation action [49]. Ideation can be organically led by employees or systematically governed by the management team. Regardless, the goal of the ideation process is to produce as many good ideas as possible for subsequent selection and decision-making [50]. By producing more ideas, organizations increase the likelihood of producing new products or services [9]. However, a vast amount of work is needed to fully develop a new idea for implementation. Therefore, the innovation process can be enhanced when organizations explicitly align their idea generation and selection process using ESN capabilities with their innovation strategies [51].

ESNs also offer a group of features that enable employees to collaborate in developing new ideas [52], [53]. Ideation without collaboration does not typically result in innovation since innovation requires the participation of different functional units [17]. ESN use can lead to greater collaboration in knowledge sharing and resource integration than traditional knowledge management systems and thus facilitate the innovation process [9]. In this study we differentiate ideation and collaboration based on their goals. While intention to ideate is centered around proposing a new idea, collaboration focuses on the refinement of the proposed ideas. For example, brainstorming process can be enabled or facilitated by two different groups of ESN features that afford both ideation and collaboration.

Socialization affordances of ESNs enable connections between employees, establish trust among them, and facilitate networking [5], [54]. Without socialization, employees may miss opportunities to learn about their colleagues' ideas, experience, and potential support [15], [55]. ESNs help increase employees' experiential communication which is essential to establish the culture of transparency and knowledge-sharing [5]. While collaboration is a goaloriented activity, socialization is interest-oriented which can happen independently from ideation in order to learn about each other's competencies before extending an invitation for collaboration [56].

\section{Hypotheses}

In this section, we propose a theoretical model that depicts how ESN applications could potentially support innovation productivity. Our model explains the mechanism that links ESN applications to Innovation Productivity through its support and enhancement of Innovation Culture. This model is grounded by the Stimulus-Organism-Response (SOR) theory, as well as the organizational culture theory the latter of which shows the dynamic relationship between environmental stimuli (ES), organization culture, and subsequent behavior [57]-[59]. 


\subsection{ESN and Innovation Culture.}

ESN applications have changed many organizations' capacity to innovate in recent years [60]. Given their relevance and contribution to business success long-term, the impact of ESNs on organizational culture has been recognized as a serious factor in management and organizational development [34]. One of the keys to implementing the desire to innovate in the workplace is turning innovation into a habit among employees. In an environment marked by habitual creativity, employees are encouraged to innovate while feeling involved and valued [3]. ESNs allow new possibilities in communication styles, knowledge exchanges, collaboration, acquiring information, and networking through unique social media characteristics such as visibility, persistence, editability, and association [61], [62].

Spontaneous interactions on ESNs are important factors boosting ideation. Ideation, when enabled through social interaction via ESN application, promotes a culture of transparency, knowledgesharing, and risk-taking [51]. Among the benefits of ESN-facilitated social interaction is an increase in employee confidence in ideation. Thus, when employees realize their contributions are appreciated, they are prompted to more creative and active involvement in the collaborative innovation process.

Collaboration also can be supported by different features of ESNs that allow brainstorming, dialogue, and meta-voicing [63]. Collaboration increases employee confidence in risk taking when receiving informal support from their peers across the organization [64]. Moreover, collaboration via ESN facilitation is one of the drivers that forms a culture of trust in sharing knowledge and opinions and asking for help or support. Knowledge-sharing enabled by socialization can be deemed a factor of both informal and formal exchange around new ideas, initiatives, or goals [63]. Throughout this process, ESNs make socialization between individuals easier, streamlined, and stored for future references. Thus, an organizational culture of innovation may be enhanced by a higher level of interactions and meaningful exchange between employees across different units; therefore, we hypothesize that:

H1a: ESN-enabled ideation fosters innovative culture.

H1b: ESN-enabled collaboration fosters innovative culture.

H1c: ESN-enabled socialization fosters innovative culture.

\subsection{Innovation Culture and Innovation Productivity}

Innovation productivity is considered a cornerstone of growth for many organizations [65]. Acknowledging that innovation productivity is driven by various factors, we focus on innovation productivity as one of the understudied elements in the context of ESN. An organization that leverages technological affordances to build a culture of innovation empowers its employees to boost innovation productivity [34], [66]. It is expected that digital technologies including ESN applications can indirectly drive innovative productivity by affecting the culture of innovation within an organization [60].

Innovation culture increases employees' productivity in myriad tasks, from creative problemsolving to cost reduction. In this paper, we chiefly argue that in order to boost innovation productivity, organizations can and should implement ESN technologies and platforms that facilitate knowledge sharing, transparency, and risk tolerance. Further research supports this claim by suggesting that socialization in conjunction with collaboration can improve knowledge transfer and effect innovation [54]. Further, innovation productivity is enhanced in a culture that promotes openness, trust, and error tolerance. Cultures that openly support innovation endeavors without penalizing failures open new opportunities for experimentation with innovative ideas. This increases the chance of success especially in the development of new processes. This proinnovation culture approach bolsters higher new product development [67]. Therefore, we expected:

\section{H2a: Innovation culture enhances innovation in terms of new product/service development.}

$\boldsymbol{H} 2 \boldsymbol{b}$ : Innovation culture enhances innovation in terms of new process development.

H2c: Innovation culture enhances innovation in terms of social impact development.

\section{$4 \quad$ Method}

We tested our hypotheses using data collected from an international survey panel distributed through LinkedIn. The survey included screening questions to ensure participants were from a medium to large organization with at least one year of experience with one ESN platform. Research showed that the data collected from LinkedIn is comparable in terms of quality with other paid industrial survey panels commonly used for empirical research [68].

We modeled ESN use as three reflective first-order constructs (ideation, collaboration, and socialization), innovation culture as a formative second-order construct with three first-order reflective constructs (knowledge-sharing, transparency and risk tolerance) and innovation productivity as three first-order reflective constructs (product/service innovation, process innovation and social innovation). The model specification is reported in Table 1. 
The instrument items were adapted from previous studies and pre-tested for face validity and content validity using an expert panel [69]. The expert panel consisted of 10 researchers from our research lab. In the next validity test phase, the instrument was pilot tested to establish the scale reliability and construct validity for the first-order constructs [70]. The pilot study also helped to test the indicator validity and multicollinearity for innovation culture, the secondorder formative construct [70]. The sample for the pilot study was drawn from a LinkedIn community, and data were collected online. The refined version of the instrument was used for the filed test. We repeated the same process to establish the reliability and validity after the field test. After validating the measurement model, we employed Partial Least Squares (PLS) to test our hypotheses using SmartPLS 3.0 [71]. PLS analysis is preferred over other analytical techniques for two reasons: first, PLS simultaneously assesses the psychometric properties of the measurement items (i.e. the measurement model) and analyzes the direction and strength of the hypothesized relationships (i.e. the predictive validity model), and second PLS facilitates the modeling of formative constructs [72], [73].

Table 1. Constructs Definition and Specification

\begin{tabular}{|c|c|c|}
\hline CONSTRUCT & DIMENSIONS & $\begin{array}{l}\text { EXAMPLES FROM PREVIOUS STUDIES } \\
\end{array}$ \\
\hline \multirow{3}{*}{$\begin{array}{c}\text { ESN } \\
\text { APPLICATIONS }\end{array}$} & $\begin{array}{l}\text { Ideation: The process of forming or } \\
\text { entertaining new ideas to solve problems }\end{array}$ & $\begin{array}{l}\text { Organization and innovation [8]; Ideation and problem } \\
\text { solving [17], [50]; Innovation strategies [51] }\end{array}$ \\
\hline & $\begin{array}{l}\text { Collaboration: Working with others to solve } \\
\text { problems or propose new solutions }\end{array}$ & $\begin{array}{l}\text { Collaborate in developing new solutions [52], [53]; ESNs } \\
\text { support collaboration [74] }\end{array}$ \\
\hline & $\begin{array}{l}\text { Socialization: Networking and knowledge } \\
\text { sharing to learn about new possibilities }\end{array}$ & $\begin{array}{l}\text { Socialization affordances [5], [54]; ESN and Increase } \\
\text { employees' communication [5][75] }\end{array}$ \\
\hline \multirow{3}{*}{$\begin{array}{l}\text { INNOVATION } \\
\text { CULTURE }\end{array}$} & $\begin{array}{l}\text { Knowledge Sharing: Employees exchanging } \\
\text { knowledge within an organization }\end{array}$ & $\begin{array}{l}\text { Cultures and Attitudes/Fostering Innovation [35]; } \\
\text { Enhancing Collaboration and Engagement [36], [37] }\end{array}$ \\
\hline & $\begin{array}{l}\text { Transparency: Openness in reporting on new } \\
\text { ideas or failures and offering feedback }\end{array}$ & $\begin{array}{l}\text { Transparency and Boundaries [38], [39]; Managerial } \\
\text { Concerns [40] }\end{array}$ \\
\hline & $\begin{array}{l}\text { Risk Tolerance: Being comfortable in taking } \\
\text { risk to ideate }\end{array}$ & $\begin{array}{l}\text { Failure and Innovation [44]; Risk and Change [45]; Risk- } \\
\text { taking Culture [46]; Retaining Talent [8] }\end{array}$ \\
\hline \multirow{3}{*}{$\begin{array}{l}\text { INNOVATION } \\
\text { PRODUCTIVITY }\end{array}$} & $\begin{array}{l}\text { Product/Service Innovation: Bring a new } \\
\text { product or service to the marketplace }\end{array}$ & Product Development [6], [33], [76] \\
\hline & $\begin{array}{l}\text { Process Innovation: A new or significantly } \\
\text { improved production or delivery method }\end{array}$ & $\begin{array}{l}\text { Enhanced Organizational Performance and Growth [22], } \\
\text { [23] }\end{array}$ \\
\hline & $\begin{array}{l}\text { Social Innovation: Meet social needs in a } \\
\text { better way than the existing solutions }\end{array}$ & Social Impact [28]; Investment in Green Initiatives [77] \\
\hline
\end{tabular}

\section{$5 \quad$ Results}

\subsection{Pilot Study}

Following the pre-test, we conducted a pilot study to initially assess the instrument's reliability. Out of 107 invitations, we received 53 usable responses. We constructed all items as seven-point Likert-scale questions to avoid collapsed variance and maintain consistency. The data were normally distributed, which indicates that we obtained a reasonable sample size for multivariate analysis with PLS [78]. We tested the measurement model in two steps: 1) first-order reflective construct examination and latent variables estimation, and 2) formative second-order constructs [73]. We calculated Cronbach's alpha and performed composite reliability tests to test the data's reliability for the first-order constructs [79]. We also assessed convergent validity by examining the average variance extracted (AVE) and discriminant validity by using the Fornell-Larcker criterion. The pilot-test helped us to remove or adjust 11 items before the field test.
To evaluate innovation culture, the second-order formative construct, we assessed the formative measurement items' validity, multicollinearity, and redundancy. We estimated indicator validity using the PLS algorithm method with bootstrapping to calculate item weights and the loading of each formative indicator, knowledge-sharing, transparency and risk tolerance. The t-values for each item's weight (relative importance) and loading (absolute importance) were significant. Multicollinearity tests showed that each indicator's variance inflation factor (VIF) value was less than the cut-off value of five [73].

\subsection{Field Study}

Following the instrument refinement, we conducted a field study to test both measurement and structural model. From 482 responses collected, we only included 432 responses from the subjects who passed our screening questions (ESN experience, ESN familiarity and organizational size). The top 5 ESN platforms used by the respondents include Workplace, 
MS Team, SocialCast, Slack, and Connection. Table 2 summarized the respondents' profiles. While our sample appears imbalanced at first sight (i.e. disparities in gender, education), it is practically representative of the current distribution of workforce demographics globally (World Bank, 2019).

Table 2. Respondents' profiles $(n=432)$

\begin{tabular}{|c|c|c|}
\hline \multirow{3}{*}{ GENDER } & Male & $70.4 \%$ \\
\hline & Female & $29.1 \%$ \\
\hline & Undisclosed & $0.5 \%$ \\
\hline \multirow{5}{*}{ AGE } & $<25$ & $12.4 \%$ \\
\hline & $25-35$ & $59.7 \%$ \\
\hline & $35-45$ & $13.3 \%$ \\
\hline & $45-55$ & $11.7 \%$ \\
\hline & $>55$ & $2.9 \%$ \\
\hline \multirow{6}{*}{ EDUCATION } & High school & $3.7 \%$ \\
\hline & Associates Degree & $4.8 \%$ \\
\hline & Bachelor's Degree & $61.0 \%$ \\
\hline & Master's Degree & $28.5 \%$ \\
\hline & Doctorate Degree & $1 \%$ \\
\hline & Undisclosed & $1 \%$ \\
\hline \multirow{5}{*}{ LOCATION } & North America & $40.4 \%$ \\
\hline & Asia & $33.6 \%$ \\
\hline & South America & $17.5 \%$ \\
\hline & Europe & $6.4 \%$ \\
\hline & Africa & $2.1 \%$ \\
\hline \multirow{6}{*}{ EXPERIENCE } & $0-5$ & $28.6 \%$ \\
\hline & $5-10$ & $45.7 \%$ \\
\hline & $10-15$ & $11.4 \%$ \\
\hline & $15-20$ & $7.4 \%$ \\
\hline & $20-25$ & $3.8 \%$ \\
\hline & $25+$ & $3.1 \%$ \\
\hline
\end{tabular}

5.2.1 Measurement Model. The evaluation of reflective constructs involved the test of construct reliability (item reliability and internal consistency), construct factorability, and construct validity (convergent validity and discrimination validity). All the loadings of measurement items on their latent constructs were found to exceed 0.7 , indicating acceptable item reliability. As shown in Table 3, Cronbach's alpha and the composite reliability of all the constructs are higher than 0.7 , indicating adequate internal consistency among the items measuring each construct.

Three criteria were adopted to assess convergent validity and discriminant validity. First, all Average Variance Extracted (AVE) values are higher than 0.5. Second, the square root of the AVE of each construct is larger than the correlations of this construct with the other constructs [78]. Third, the correlations among all constructs (i.e., inter-construct correlations) are well below the 0.9 threshold. The results of these tests suggest adequate convergent and discriminant validity. We tested for common method bias using a full collinearity assessment (i.e., vertical and lateral). All the pathological VIFs resulting from the full collinearity test were lower than the 3.3 threshold, suggesting the absence of common method bias [80]. Therefore, substantial common method variance is not present.

The evaluation of formative measurementsmeasurements of Innovation Culture-involves an assessment of the formative indicators' validity and multicollinearity. Indicator validity, which gauges the strength and significance of the path from the indicator to the construct, was estimated using the PLS algorithm method with a bootstrapping of samples to calculate the weight (relative importance) and loading (absolute importance) of each indicator on its corresponding construct. The indicators' weights represent the partialized effect of the subscales on the affordance construct, controlling for the effect of all other indicators. As shown in Table 4, the significance of weights indicated the relevance of all indicators in measuring the perceived values. Multicollinearity among indicators was also calculated for these formative constructs by computing the Variance Inflation Factor (VIF) of each indicator. All computed VIF values are well below the conservative threshold of 5.0, suggesting that multicollinearity is not a threat to the validity of the study's findings [78].

Table 3. Psychometric properties of 1st-order constructs

\begin{tabular}{lllll}
\hline CONSTRUCT & & AVE & $\boldsymbol{\alpha}$ & CR \\
\hline ESN \\
Applications & Collaboration & 0.67 & 0.75 & 0.86 \\
\cline { 2 - 5 } & Ideation & 0.65 & 0.73 & 0.85 \\
\cline { 2 - 5 } $\begin{array}{l}\text { Socialization } \\
\text { Innovation }\end{array}$ & 0.57 & 0.75 & 0.84 \\
\hline $\begin{array}{l}\text { Knowledge } \\
\text { Sharing }\end{array}$ & 0.58 & 0.76 & 0.85 \\
\cline { 2 - 5 } & Risk Tolerance & 0.59 & 0.83 & 0.88 \\
\cline { 2 - 5 } $\begin{array}{l}\text { Innovation } \\
\text { Productivity }\end{array}$ & $\begin{array}{l}\text { Product/Service } \\
\text { Innovation }\end{array}$ & 0.64 & 0.81 & 0.88 \\
\cline { 2 - 5 } & $\begin{array}{l}\text { Process } \\
\text { Innovation }\end{array}$ & 0.67 & 0.76 & 0.86 \\
\cline { 2 - 5 } & $\begin{array}{l}\text { Social (Impact) } \\
\text { Innovation }\end{array}$ & 0.64 & 0.72 & 0.84 \\
\hline
\end{tabular}

Table 4. Weights and Loadings of the Formative Indicators

\begin{tabular}{cccc}
\hline INDICATOR & VIF & LOADINGS* & WEIGHTS \\
\hline KNS & 2.64 & 0.89 & 0.30 \\
TRA & 3.07 & 0.94 & 0.46 \\
RIT & 2.82 & 0.91 & 0.33 \\
\hline${ }^{*} p<0.001$ level & & &
\end{tabular}

5.2.2 Structural Model. To test the proposed theoretical model, we examined the direct and indirect 
effects of ESN on Innovation Culture and innovation productivity, accounting for control variables like demographic, job role, industry profile, and platform. The results revealed that the ESN Applications construct is positively associated with Innovation Culture through Ideation $(\beta=0.17, p<0.001$, Collaboration $(\beta=0.23, p<0.001)$, and Socialization $(\beta=0.51, p<0.001)$. The findings thus supported hypotheses $\mathrm{H}_{1} \mathrm{a}, \mathrm{H}_{1} \mathrm{~b}$, and $\mathrm{H}_{1}$.

The findings also supported the significant positive effect of innovation culture on innovation productivity in terms of Product/Service Innovation $(\beta$
$=0.41, p<0.001)$, Process Innovation $(\beta=0.51, p<$ $0.001)$, and Social Innovation $(\beta=0.42, p<0.001)$. Thus, the results supported hypotheses $\mathrm{H}_{2 \mathrm{a}}, \mathrm{H}_{2} \mathrm{~b}, \mathrm{H} 2 \mathrm{c}$. These findings suggest Innovation Culture has a significant impact on Innovation Productivity $\left(R^{2}=\right.$ $68 \%, R^{2}=55 \%$, and $R^{2}=56 \%$ ). We also examined the significance of the nine indirect effects by using bootstrapping (i.e. the indirect effects of ESN dimensions of innovation productivity dimensions). The indirect effects sizes ranged from 0.12 to 0.25 and were significant at $p<0.001$ level.

Table 5. Results of the Structural Model Assessment

\begin{tabular}{llllll}
\hline \multicolumn{1}{c}{ DEPENDENT VARIABLE } & HYPOTHESIS & SUPPORT & $\mathbf{B}$ & $\mathbf{t}^{2}$ & $\mathbf{R}^{\mathbf{2}}$ \\
\hline ESN & H1a: IDA $\rightarrow$ INC & Supported & $0.27^{* * *}$ & 5.17 \\
(ESN Applications) & H1b: COA $\rightarrow$ INC & Supported & $0.22^{* * *}$ & 4.87 & 0.69 \\
\hline \multirow{2}{*}{ INC } & H1c: SOA $\rightarrow$ INC & Supported & $0.44^{* * *}$ & 8.77 & \\
(Innovation Culture) & H2a: INC $\rightarrow$ PSI & Supported & $0.83^{* * *}$ & 42.94 & 0.68 \\
& H2b: INC $\rightarrow$ PRI & Supported & $0.74^{* * *}$ & 26.40 & 0.55 \\
\hline
\end{tabular}

$* p<0.05 ; * * p<0.01 ; * * * p<0.001 ; \beta=$ path coefficients; $R^{2}=$ determination coefficient.

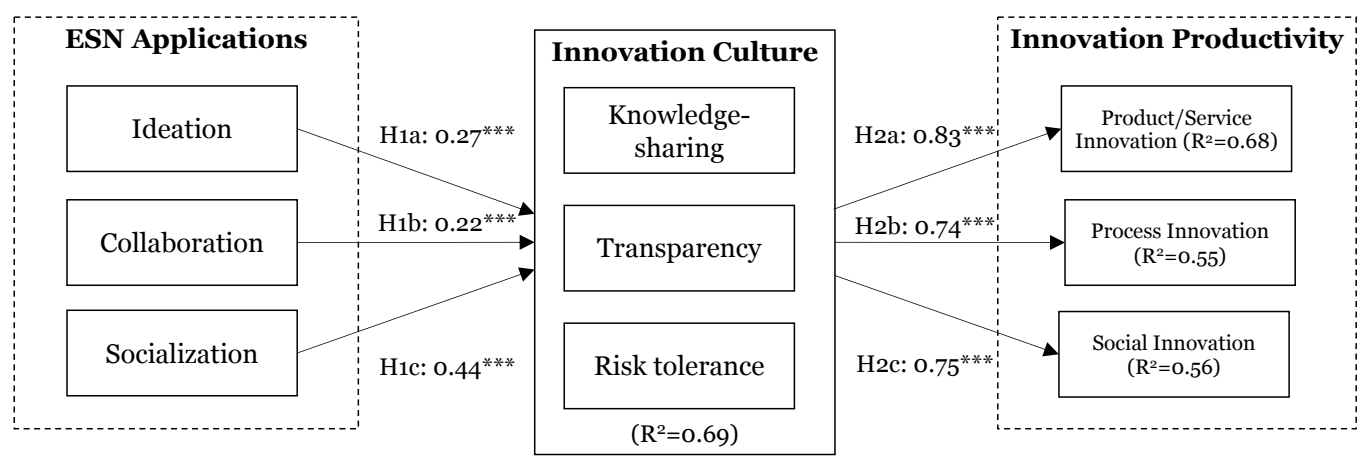

Figure 1. Theoretical Model

\section{Discussion}

ESN platforms that afford ideation, collaboration and socialization are likely to foster a culture that supports innovation, leading to a more productive innovation environment. These platforms support and provide affordances for a culture of innovation that prioritizes knowledge-sharing, transparency and risktaking. This study suggests while ESNs do not systematically support innovation, they indirectly drive innovation by improving innovation culture in total. The three ESN-facilitated mechanisms identified here (ideation, collaboration, and socialization) can individually and collectively explain how innovation culture is formed by using this technology.

Ideation enabled by ESN applications empowers employees to be more active in sharing their ideas openly with their colleagues. Collaboration is also facilitated by ESN applications. ESN supports transparency and encourages knowledge-sharing beyond the boundaries of functional units that in turn contribute to innovation productivity. ESN also allows employees to socialize and network with their peers in a way that was not possible before. This, if wellimplemented and monitored, allows employees to feel trusted and safe in sharing their opinions regarding different business challenges and possible solutions. Moreover, our study confirmed the earlier findings on the role of innovation culture in driving innovation. However, contributing to the literature, we conceptualized innovation productivity as product/service innovation, process innovation, and social innovation and empirically showed the significant indirect effect of ESN on each. This study thus suggests the application of ESN beyond new product development 


\section{Contributions and Implications}

This study contributes to ESN, innovation, and management literature. The model proposed by this paper, in particular, offers a straightforward but comprehensive approach to modeling ESN application effectiveness for fostering innovation based on their core functionalities. Our proposed approach is not only grounded in theory but also flexible enough to help study different ESN platforms, as we acknowledged during the formulation of this model that ESN platforms come in different forms and with different level of emphasis on ideation, collaboration and socialization. Despite this, our study supports the claim that ESN platforms, regardless of orientation, can drive innovation culture. However, the most prominent effect on innovation culture is associated with the ESN platforms that afford socializing among employees.

Our findings also explain why prior studies involving innovation culture and productivity arrived at mixed conclusions about the role of ESN platforms in improving innovation practices. To this point, our research group contends that ESN applications are not the necessarily drivers of innovation. Instead, if carefully selected and strategically implemented, an ESN application can affect the organizational culture and make the associated organizational environment one that emphasizes transparency, knowledge sharing, and risk taking. Given this type of environment, technology such as ESN applications can help creativity flourish to the benefit of innovation culture and productivity. This impact would not be limited to new products/services but would also help employees to creatively redesign internal processes and enhance the social footprint of the organization.

This study also offers some implications for practice which are critical in the era of virtual work and distributed teams. First, this study supports the use of ESN for employee empowerment with emphasis on cross-departmental ideation, collaboration and socialization. Second, organizations can consider the use of ESN as an investment for enhancing organizational culture. However, the benefits of ESN may go beyond boosting innovation culture and affect other aspects of organizational behavior such as accountability, responsibility, and agility which become increasingly important during and after the COVID-19 pandemic. Third, our study provides a simple roadmap on how to plan and implement ESN for open innovation. ESNs can be retooled and solely used to feed the innovation pipeline when they enable employees to streamline their informal ideation activities. These all lead to furthering an environment of innovation culture and thus innovation productivity. Fourth, organizations can use our simple model to evaluate different ESN applications that best fit their organizational innovation needs. For example, by using our proposed instrument, organization can go beyond usage metric when evaluating the role and impact of ESN in changing organization culture and behavior.

\section{$8 \quad$ Limitations and Future Research}

Our survey-based method involves a number of limitations that could be addressed by future research. First, the use of ESN technology is emergent and has a wide range of potential applications; therefore, it is difficult to generalize our findings beyond the context of innovation. Second, this study is exploratory nature and so our model needs further evaluation and refinement based on future study and evidence. Third, we only considered positive aspects of ESN application usage in conducting this study. Future studies can and should address this limitation by using constructs presented here as a baseline for conducting evaluations of negative consequences of ESN use. Finally, the systematic implementation of ESN apps for innovation is challenging in terms of time, coordination, and training, just to name a few examples. As a result, this process may be contingent on factors that were not discussed in this study.

Future researchers can further develop our model and empirically examine the influence of ESN applications on innovation culture and innovation productivity, hopefully to refine and support the model's assertions. The research community can also determine which ESN affordances result in a greater innovative culture and therefore inform the design and applications. Examining different types of ESN applications could also be beneficial in describing how the specific affordances are affecting different characteristics of innovation culture. Some other variables, such as management support and innovation resources, can be considered in future iterations and offshoots of this model.

\section{References}

[1] McKinsey \& Company, "Growth \& Innovation," Strategy \& Corporate Finance. 2020.

[2] S. Dittes and S. Smolnik, "Towards a digital work environment: the influence of collaboration and networking on employee performance within an enterprise social media platform," J. Bus. Econ., vol. 89, no. 8-9, pp. 1215-1243, 2019.

[3] M. Tian, P. Deng, Y. Zhang, and M. P. Salmador, "How does culture influence innovation? A systematic literature review," Management Decision, vol. 56, no. 5. pp. 1088-1107, 2018.

[4] Y. Sun, X. Zhou, A. Jeyaraj, R. A. Shang, and F. Hu, "The impact of enterprise social media platforms on knowledge sharing: An affordance lens perspective," Journal of Enterprise Information Management, vol. 32, no. 2. Emerald 
Group Publishing Ltd., pp. 233-250, Apr-2019.

[5] A. Engelbrecht, J. P. Gerlach, A. Benlian, and P. Buxmann, "How employees gain meta-knowledge using enterprise social networks: A validation and extension of communication visibility theory," J. Strateg. Inf. Syst., vol. 28, no. 3, pp. 292 309, 2019.

[6] A. Baregheh, J. Rowley, and S. Sambrook, "Towards a multidisciplinary definition of innovation," Manag. Decis., vol. 47, no. 8, pp. 1323-1339, 2009.

[7] M. Mpandare and G. Li, "Utilising enterprise social media for product innovation: The role of market orientation," Sustainability, vol. 12, no. 9, p. 3913, May 2020.

[8] J. Recker, A. Malsbender, and T. Kohlborn, "Using Enterprise Social Networks as Innovation Platforms," IT Prof., vol. 18, no. 2, pp. 42-49, 2016.

[9] N. Rahman, "Understanding the Impact of Knowledge Sharing through Enterprise Social Networking (ESN) on Service Innovation," in Proceedings of the 53rd Hawaii International Conference on System Sciences, 2020.

[10] A. H. Pitafi, A. N. Khan, N. A. Khan, and M. Ren, "Using enterprise social media to investigate the effect of workplace conflict on employee creativity," Telemat. Informatics, p. 101451, Jun. 2020.

[11] K. Abhari, E. J. Davidson, and B. Xiao, "Modeling Social Product Development Process, Technology, and Governance," IEEE Trans. Eng. Manag., pp. 1-14, 2020.

[12] M. C. Annosi, G. Marzi, F. Ciampi, and R. Rialti, "An Ambidextrous Approach to Practice-Based Innovation for Social Product Development: Lessons From A Dutch Company," IEEE Trans. Eng. Manag., pp. 1-12, 2020.

[13] T. J. V Saldanha, A. Sahaym, S. Mithas, M. G. Andrade-Rojas, A. Kathuria, and H.-H. Lee, "Turning Liabilities of Global Operations into Assets: IT-Enabled Social Integration Capacity and Exploratory Innovation," Inf. Syst. Res., vol. 31, no. 2, pp. 297-652, 2020.

[14] M. L. Markus and M. S. Silver, "A Foundation for the Study of IT Effects: A New Look at DeSanctis and Poole's Concepts of Structural Features and Spirit," J. Assoc. Inf. Syst., vol. 9, no. $10 / 11$, pp. 609-632, 2008.

[15] D. E. Leidner, E. Gonzalez, and H. Koch, "An affordance perspective of enterprise social media and organizational socialization," J. Strateg. Inf. Syst., vol. 27, no. 2, pp. 117-138, Jun. 2018.

[16] J. Burgess, A. Marwick, T. Poell, T. Bucher, and A. Helmond, "The Affordances of Social Media Platforms," in The SAGE Handbook of Social Media, London and New York: SAGE Publications Ltd, Ed. SAGE, 2017, pp. 233-253.

[17] K. Abhari, E. J. Davidson, and B. Xiao, "Co-Innovation Platform Affordances: Developing a Conceptual Model and Measurement Instrument,” Ind. Manag. Data Syst., vol. 117, no. 5, pp. 873-895, 2017.

[18] S. Lokuge, D. Sedera, V. Grover, and X. Dongming, "Organizational readiness for digital innovation: Development and empirical calibration of a construct," Inf. Manag., vol. 56, no. 3, pp. 445-461, Apr. 2019.

[19] J. W. Treem, S. L. Dailey, C. S. Pierce, and P. M. Leonardi, "Bringing technological frames to work: How previous experience with social media shapes the technology's meaning in an organization," J. Commun., vol. 65, no. 2, pp. 396-422, 2015.

[20] P. M. Leonardi, M. Huysman, and C. Steinfield, "Enterprise social media: Definition, history, and prospects for the study of social technologies in organizations," J. Comput. Commun., vol. 19, no. 1, pp. 1-19, Oct. 2013.

[21] M. Barrett, E. J. Davidson, J. Prabhu, and S. L. Vargo, "Service Innovation in the Digital Age: Key Contributions and Future Directions," MIS Q., vol. 39, no. 1, pp. 135-154, 2015.

[22] P. Rujirawanich, R. Addison, and C. Smallman, "The effects of cultural factors on innovation in a Thai SME," Manag. Res. Rev., vol. 34, no. 12, pp. 1264-1279, 2011.
[23] Y. Snihur and J. Wiklund, "Searching for innovation: Product, process, and business model innovations and search behavior in established firms," Long Range Plann., vol. 52, no. 3, pp. 305-325, Jun. 2019.

[24] P. M. Leonardi, "When Does Technology Use Enable Network Change in Organizations? A Comparative Study of Feature Use and Shared Affordances," MIS Q., vol. 37, no. 3, pp. 749-776, 2013.

[25] M. Au-Yong-Oliveira, R. Gonçalves, J. Martins, and F. Branco, "The social impact of technology on millennials and consequences for higher education and leadership," Telemat. Informatics, vol. 35, no. 4, pp. 954-963, Jul. 2018.

[26] M. A. Mamun and J. M. Shaikh, "Reinventing Strategic Corporate Social Responsibility," J. Econ. Manag. Perspect., vol. 12, no. 2, pp. 499-512, 2018.

[27] M. Gasparin, W. Green, S. Lilley, M. Quinn, M. Saren, and C. Schinckus, "Business as unusual : A business model for social innovation," J. Bus. Res., no. January, pp. 0-1, 2020.

[28] M. E. B. Herrera, "Creating competitive advantage by institutionalizing corporate social innovation," J. Bus. Res., vol. 68 , no. 7, pp. 1468-1474, 2015.

[29] F. Lettice and M. Parekh, "The social innovation process: themes, challenges and implications for practice," Int. J. Technol. Manag., vol. 51, no. 1, p. 139, 2010.

[30] A. Turró, D. Urbano, and M. Peris-Ortiz, "Culture and innovation: The moderating effect of cultural values on corporate entrepreneurship," Technol. Forecast. Soc. Change, 2014.

[31] R. Patrício, A. C. Moreira, and F. Zurlo, "Gamification approaches to the early stage of innovation," Creat. Innov. Manag., vol. 27, no. 4, pp. 499-511, Dec. 2018.

[32] T. Büschgens, A. Bausch, and D. B. Balkin, "Organizational culture and innovation: A meta-analytic review," Journal of Product Innovation Management, vol. 30, no. 4. pp. 763-781, 2013.

[33] A. J. Verdu-Jover, L. Alos-Simo, and J. M. Gomez-Gras, "Adaptive culture and product/service innovation outcomes," Eur. Manag. J., vol. 36, no. 3, pp. 330-340, 2018.

[34] H. Aksoy, "How do innovation culture, marketing innovation and product innovation affect the market performance of small and medium-sized enterprises (SMEs)?," Technol. Soc., vol. 51, pp. 133-141, 2017.

[35] I. Estrada, D. Faems, and P. de Faria, "Coopetition and product innovation performance: The role of internal knowledge sharing mechanisms and formal knowledge protection mechanisms," Ind. Mark. Manag., vol. 53, pp. 56-65, 2016.

[36] M. L. Monica Hu, J. S. Horng, and Y. H. Christine Sun, "Hospitality teams: Knowledge sharing and service innovation performance," Tour. Manag., vol. 30, no. 1, pp. 41-50, 2009.

[37] N. A. Khan and A. N. Khan, "What followers are saying about transformational leaders fostering employee innovation via organisational learning, knowledge sharing and social media use in public organisations?," Gov. Inf. Q., vol. 36, no. 4, p. 101391, 2019.

[38] C. P. Y. Chin, N. Evans, and K. K. R. Choo, "Enterprise social networks: A successful implementation within a telecommunication company," 2015 Am. Conf. Inf. Syst, 2015.

[39] A. Liew, "Enhancing and enabling management control systems through information technology: The essential roles of internal transparency and global transparency," Int. J. Account. Inf. Syst., vol. 33, pp. 16-31, 2019.

[40] R. (Irene) Zhong, "Transparency and firm innovation," $J$. Account. Econ., vol. 66, no. 1, pp. 67-93, 2018.

[41] J. Hacker and K. Riemer, "Identification of User Roles in Enterprise Social Networks: Method Development and Application," Bus. Inf. Syst. Eng., 2020.

[42] G. Ding, H. Liu, Q. Huang, and J. Gu, "Enterprise social networking usage as a moderator of the relationship between work stressors and employee creativity: A multilevel study," Inf. Manag., vol. 56, no. 8, 2019. 
[43] M. G. Aboelmaged, "Knowledge sharing through enterprise social network (ESN) systems: motivational drivers and their impact on employees' productivity," J. Knowl. Manag., vol. 22, no. 2, pp. 362-383, 2018.

[44] W. Biemans and A. Griffin, "Innovation practices of B2B manufacturers and service providers: Are they really different?," Ind. Mark. Manag., vol. 75, pp. 112-114, 2018.

[45] S. Shane, "Cultural influences on national rates of innovation," J. Bus. Ventur., vol. 8, no. 1, pp. 59-73, 1993.

[46] E. L. Coras and A. D. Tantau, "A Risk Mitigation Model in SME'S Open Innovation Projects," Manag. Mark., vol. 8, no. 6, pp. 303-328, 2013.

[47] N. B. Ellison, J. L. Gibbs, and M. S. Weber, "The Use of Enterprise Social Network Sites for Knowledge Sharing in Distributed Organizations," Am. Behav. Sci., vol. 59, no. 1, pp. 103-123, 2015.

[48] A. Richter and K. Riemer, "The contextual nature of enterprise social networking: A multi case study comparison," ECIS 2013 - Proc. 21st Eur. Conf. Inf. Syst., no. June, 2013.

[49] E. Karahanna, S. X. Xu, Y. Xu, and N. Zhang, "The needsaffordances-features perspective for the use of social media," MIS Q., vol. 42, no. 3, pp. 737-756, 2018.

[50] N. A. Rozaidi, J. L. Gibbs, and J. Eisenberg, “Accept or Reject? Predicting Ideation Outcomes through Enterprise Social Media," in International Conference on Communication and Media, 2017.

[51] A. Kock, W. Heising, and H. G. Gemünden, "How ideation portfolio management influences front-end success," J. Prod. Innov. Manag., vol. 32, no. 4, pp. 539-555, Jul. 2015.

[52] Y. Li, H. Li, N. Liu, and X. Liu, "Important institutions of interinstitutional scientific collaboration networks in materials science," Scientometrics, vol. 117, no. 1, pp. 85-103. 2018.

[53] M. Håkansson Lindqvist, "School leaders' practices for innovative use of digital technologies in schools," Br. J. Educ. Technol., vol. 50, no. 3, pp. 1226-1240, 2019.

[54] A. Dingler and E. Enkel, "Socialization and innovation: Insights from collaboration across industry boundaries," Technol. Forecast. Soc. Change, vol. 109, pp. 50-60, 2016.

[55] S. W. Futures, "How the workplace can improve collaboration," 2010

[56] K. Abhari and E. J. Davidson, "Creative Co-production: The Adaption of an Open Innovation Model in Creative Industries," in Information Systems and Management in Media and Entertainment Industries, Springer, 2016, pp. 119-130.

[57] D. Dauber, G. Fink, and M. Yolles, "A configuration model of organizational culture," $S A G E$, vol. 2, no. 1, pp. 1-16, 2012.

[58] S. Kamboj, B. Sarmah, S. Gupta, and Y. Dwivedi, "Examining branding co-creation in brand communities on social media: Applying the paradigm of Stimulus-Organism-Response," Int. J. Inf. Manage., vol. 39, pp. 169-185, Apr. 2018.

[59] J. Jacoby, "Stimulus-Organism-Response Reconsidered: An Evolutionary Step in Modeling (Consumer) Behavior," $J$. Consum. Psychol., vol. 12, no. 1, pp. 51-57, Jan. 2002.

[60] N. F. Garmann-Johnsen, M. Helmersen, and T. R. Eikebrokk, "Employee-driven digitalization in healthcare: codesigning services that deliver," Heal. Policy Technol. 2020.

[61] L. Giermindl, F. Strich, and M. Fiedler, "Do enterprise social networks really enhance our performance? Exploring the relationship between usage practices and individual task performance," in International Conference on Information Systems 2018, ICIS 2018, 2018, pp. 150-151.

[62] J. W. Treem and P. M. Leonardi, "Social Media Use in Organizations: Exploring the Affordances of Visibility, Editability, Persistence, and Association," in Communication Yearbook, vol. 36, C. T. Salmon, Ed. New York, 2012, pp. 143-189.

[63] Y.-M. S. Wong, "Virtual sensemaking and self-presentation on Slack : Exploring the effects of Enterprise Social Network (ESN) on workplace culture and socialisation," University of Copenhagen, 2018.
[64] F. Gao, R. O. Briggs, S. Thiebes, and A. Sunyaev, "MultiOrganizational Multi-Stakeholder Collaboration Systems: An Exploratory Research Study of Design Concerns in Healthcare," Proc. 52nd Hawaii Int. Conf. Syst. Sci., pp. 512$521,2019$.

[65] L. Carvalho and A. P. M. de Avellar, "Innovation and productivity: empirical evidence for Brazilian industrial enterprises," Rev. Adm., vol. 52, no. 2, pp. 134-147, 2017.

[66] G. Crespi and P. Zuniga, "Innovation and Productivity: Evidence from Six Latin American Countries," World Dev., vol. 40, no. 2, pp. 273-290, 2012.

[67] K. Lee, H. G. Woo, and K. Joshi, "Pro-innovation culture, ambidexterity and new product development performance: Polynomial regression and response surface analysis," Eur. Manag. J., vol. 35, no. 2, pp. 249-260, 2017.

[68] N. Unkelos-Shpigel, S. Sherman, and I. Hadar, "Finding the Missing Link to Industry: LinkedIn Professional Groups as Facilitators of Empirical Research," in Proceedings - 3rd International Workshop on Conducting Empirical Studies in Industry, 2015, pp. 43-46.

[69] D. M. Rubio, M. Berg-Weger, S. S. Tebb, E. S. Lee, and S. Rauch, "Objectifying content validity: Conducting a content validity study in social work research," Soc. Work Res., vol. 27, no. 2, pp. 94-104, Jun. 2003.

[70] J. F. Hair, G. T. M. Hult, C. M. Ringle, and M. Sarstedt, $A$ Primer on Partial Least Squares Structural Equation Modeling (PLS-SEM). Thousand Oaks: SAGE, 2013.

[71] C. Ringle, S. Wende, and J. Becker, "SmartPLS 3," Boenningstedt: SmartPLS GmbH. 2015.

[72] W. W. Chin and J. Dibbern, Handbook of Partial Least Squares, no. July. 2010.

[73] J. F. Hair, C. M. Ringle, and M. Sarstedt, "PLS-SEM: Indeed a Silver Bullet," J. Mark. Theory Pract., vol. 19, no. 2, pp. 139-152, Apr. 2011.

[74] K. Ortbach and J. Recker, "Do good things and talk about them: A Theory of Academics Usage of Enterprise Social Networks for Impression Management Tactics," ICIS 2014 Proc., Dec. 2014.

[75] C. Shum, A. Gatling, L. Book, and B. Bai, "The Moderating Roles of Follower Conscientiousness and Agreeableness on the Relationship Between Peer Transparency and Follower Transparency," J. Bus. Ethics, vol. 154, no. 2, pp. 483-495, 2019.

[76] R. Zimmermann, L. M. Luís, and A. Carrizo Moreira, "The influence of supply chain on the innovation process: a systematic literature review," Supply Chain Manag., vol. 21, no. 3, pp. 289-304, May 2016.

[77] G. Halkos and A. Skouloudis, "Corporate social responsibility and innov ative capacity: Intersection in a macro-level perspective," J. Clean. Prod., vol. 182, pp. 291-300, 2018.

[78] J. Hair, W. Black, B. Babin, and R. Anderson, "Multivariate Data Analysis: A Global Perspective," in Multivariate Data Analysis: A Global Perspective, Seventh., vol. 7th, Pearson, 2010.

[79] J. F. Hair, C. M. Ringle, and M. Sarstedt, "Partial Least Squares Structural Equation Modeling: Rigorous Applications, Better Results and Higher Acceptance," Long Range Plann., vol. 46, no. 1-2, pp. 1-12, 2013.

[80] N. Kock, "Common method bias in PLS-SEM: A full collinearity assessment approach," Int. J. e-Collaboration, vol. 11, no. 4, pp. 1-10, 2015. 